\title{
Analysis of nonlinear dynamics and chaos control in gear transmission system with stochastic perturbation
}

\author{
Jingyue WANG*, **, Haotian WANG***, Lixin GUO**** \\ *Shenyang Ligong University, Shenyang, 110159, China, E-mail: abswell@126.com \\ **The State Key Laboratory of Mechanical Transmissions, Chongqing University, Chongqing, 400044, China \\ ***Shenyang Aerospace University, Shenyang, 110136, China, E-mail: syhkwht@126.com \\ ****Northeastern University, Shenyang, 110819, China, E-mail: neuglx@126.com \\ cross $^{\text {ref }}$ http://dx.doi.org/10.5755/j01.mech.23.2.13576
}

\section{Introduction}

Gear transmission system is commonly used in automobile, robotics, machinery, aerospace and other areas. Scholars have done a lot of research on the nonlinear dynamic of gear transmission system [1-4]. Kahranman [5-7] et al. studied the dynamic response of gear transmission system under different forms of excitation. Theodossiades [8, 9] et al. investigated dynamics of a gear-pair system involving backlash and time-dependent mesh stiffness under the action of external excitation caused by torsional moments and gear geometry errors, and investigated dynamics of gear-pair systems driven by motors and presenting speeddependent moment resistance. Huang and Liu [10] treated a spur gear tooth as a variable cross-section Timoshenko beam to construct a dynamic model, being able to obtain transient response for spur gears of involute profiles and investigated the dynamic responses of a single tooth and a gear pair. Howard [11] et al. studied the influence of gear tooth surface friction on system dynamics under various conditions. Shyyaba and Kahranman [12] used a non-linear time-varying dynamic model to investigate sub-harmonic and chaotic motions exhibited by a typical multi-mesh gear train. Litak and Friswell [13] examined the effect of tooth shape imperfections and defects. Parey [14] and Eritenel [15] et al. analyzed the changes impact of time-varying mesh stiffness, friction coefficient, tooth bending, coincidence degree and modal damping parameters on the stability of the boundary. Bonori and Pellicano [16] presented a method for analysing nonlinear vibrations of spur gears in presence of manufacturing errors. However, they rarely consider the influence of system parameters perturbation on the system dynamics. In recent years, some scholars have started to study the gear system as a stochastic system [1719].

Chaotic vibration is a unique form of nonlinear dynamics system. In some cases, chaos is harmful. So we just have to adopt some methods to eliminate the chaotic vibration. Chaos control has attracted wide attention of scholars whom have proposed a lot of different control methods at home and abroad. The typical methods are mainly OGY method [20], adaptive control method [21], parametric perturbation method [22], periodic excitation method [23], continuous feedback control method [24] and so on. Because of the nonlinear variable factors such as gear clearance [9], meshing stiffness [13], time-varying mesh parameters [25], turbulent flow [26], the gear system generates the strong nonlinear vibration. In a certain parameters region, the system is characterized by chaotic vibration. However, chaotic vibration for the working performance and reliability of the transmission system is harmful. Therefore, the chaotic vibration of gear transmission system is required to be effective and feasible control. However, research on how to effectively control chaos in the gear transmission system is comparatively less.

This paper discusses the bifurcation and chaos in the single degree of freedom spur gear transmission system with stochastic perturbation of gear backlash, gear damping ratio, meshing frequency meshing stiffness and input torque fluctuation, and uses feedback control method, non-feedback control method to control chaos.

\section{Dynamic model and deferential equations of motion}

The stochastic non-linear dynamic model of a single degree of freedom gear transmission system is illustrated in Fig. 1. The lumped mass method is introduced to establish the torsional vibration model. The model is just considered the torsional vibration of gear, ignoring the transverse and axial elastic deformation of transmission shaft, tooth surface friction, as well as the supporting system of elastic deformation and other factors. The basic parameters of a gear pair are shown in Table [17].

Table

Parameters of gear pair

\begin{tabular}{|c|c|c|c|c|c|c|}
\hline Gear pair & Teeth $Z$ & $\begin{array}{c}\text { Modulus } m, \\
\mathrm{~mm}\end{array}$ & $\begin{array}{c}\text { Pressure angle } \\
\alpha^{\circ}\end{array}$ & $\begin{array}{c}\text { Coefficient of } \\
\text { addendum } h_{a}\end{array}$ & $\begin{array}{c}\text { Coefficient of tip } \\
\text { clearance } c\end{array}$ & $\begin{array}{c}\text { Tooth width } B, \\
\mathrm{~mm}\end{array}$ \\
\hline Driving gear & 35 & 3 & 20 & 1 & 0.25 & 20 \\
\hline Follower gear & 58 & 3 & 20 & 1 & 0.25 & 20 \\
\hline
\end{tabular}

According to the Newton's rule, the dynamic equations of the system are given by: 


$$
\left.\begin{array}{l}
T_{1}=I_{1} \ddot{\theta}_{1}+\left(c_{h}+c_{h \Delta}\right) R_{b 1}\left(R_{b 1} \dot{\theta}_{1}-R_{b 2} \dot{\theta}_{2}-\dot{e}(\tau)\right)+k(\tau) R_{b 1} f\left(R_{b 1} \theta_{1}-R_{b 2} \theta_{2}-e(\tau)\right)+F_{\Delta} ; \\
T_{2}=-I_{2} \ddot{\theta}_{2}+\left(c_{h}+c_{h 4}\right) R_{b 2}\left(R_{b 1} \dot{\theta}_{1}-R_{b 2} \dot{\theta}_{2}-\dot{e}(\tau)\right)-k(\tau) R_{b 2} f\left(R_{b 1} \theta_{1}-R_{b 2} \theta_{2}-e(\tau)\right) .
\end{array}\right\}
$$

In Eqs. (1), (2) and (6), a dot( (·) denotes differentiation with the time. In the system, $T_{1}$ and $T_{2}$ are the torque for the role in driving and follower gear, $R_{b 1}$ and $R_{b 2}$ are the base circle radius of driving and follower gear, $c_{h}$ is the gear pair meshing damping. $c_{h \Delta}$ is the gear pair meshing damping stochastic perturbation. $\theta_{1}$ and $\theta_{2}$ are the torsional vibration displacement. $e(\tau)$ is the gear integrated error shown in Fig. 2, $\tau$ is time. $k(\tau)$ is the gear pair time-varying meshing stiffness. $I_{1}$ and $I_{2}$ are the driving and follower gear rotation inertia. $F_{\Delta}$ is the input torque stochastic disturbance.

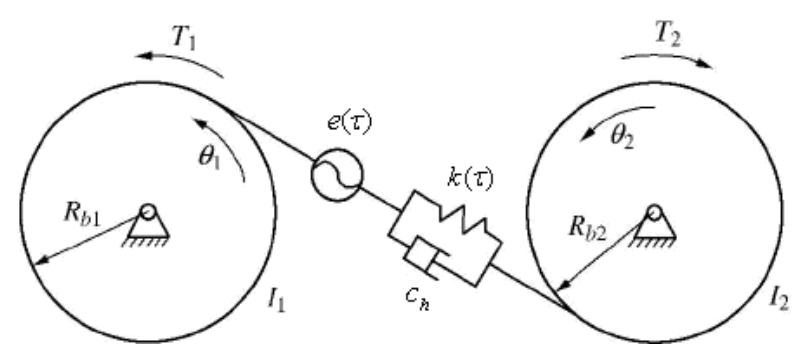

Fig. 1 A single degree of freedom stochastic non-linear dynamic model of gear transmission system

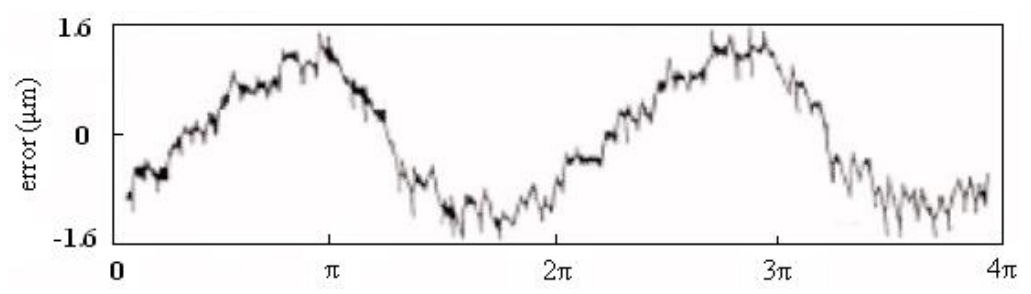

Fig. 2 The transmission error of the gear transmission system

Gear meshing force is mainly composed of the elastic meshing force $F_{1}$ caused by time-varying meshing stiffness, whereby the viscous meshing force $F_{2}$ caused by the gear dynamic load and meshing damping. The expression is:

$$
\left.\begin{array}{l}
F_{1}=k(\tau) f\left(R_{b 1} \theta_{1}-R_{b 2} \theta_{2}-e(\tau)\right) \\
F_{2}=\left(c_{h}+c_{h \Delta}\right) R_{b 2}\left(R_{b 1} \dot{\theta}_{1}-R_{b 2} \dot{\theta}_{2}-\dot{e}(\tau)\right)
\end{array}\right\}
$$

In order to eliminate the rigid body displacement, the system is treated by non-dimensional. Introduce the generalized coordinates relative of gear meshing line to the system. Suppose that

$$
\begin{aligned}
& x=\left(R_{b 1} \theta_{1}-R_{b 2} \theta_{2}-e(\tau)\right) / b_{e} ; \\
& \omega_{n}=\sqrt{\frac{k_{a v}}{m_{e}}} ; m_{e}=\frac{m_{1} m_{2}}{m_{1}+m_{2}},
\end{aligned}
$$

where $b_{e}$ is the given nominal size; $m_{e}$ is the equivalent mass; $m_{1}$ and $m_{2}$ are respectively the driving and follower gear quality; $\omega_{n}$ is the natural frequency of the system; $k_{a v}$ is the average mesh stiffness of the gear pair. Let $t=\omega_{n} \tau$, $\bar{b}=b / b_{e}, \omega_{h}=\omega_{e} / \omega_{n} .2 b$ is the gear clearance, as shown in Fig. $3, \bar{b}$ is the non-dimensional gap, $\omega_{h}$ is the meshing frequency, $\omega_{e}$ is the meshing frequency of the gear pair.

Clearance nonlinear function is:

$$
f(x)=\left\{\begin{array}{lc}
x-\left(\bar{b}+\bar{b}_{\Delta}\right), & x>\bar{b}+\bar{b}_{\Delta} ; \\
0, & -\bar{b}-\bar{b}_{\Delta} \leq x \leq \bar{b}+\bar{b}_{\Delta} ; \\
x+\left(\bar{b}+\bar{b}_{\Delta}\right), & x<-\bar{b}-\bar{b}_{\Delta},
\end{array}\right.
$$

where $\bar{b}_{\Delta}$ is the dimensionless backlash stochastic disturbance; $\bar{b}_{\Delta}=b_{\Delta} / b_{e} ; \bar{b}_{\Delta}=b_{\Delta} / b_{e}$ is the backlash stochastic disturbance.

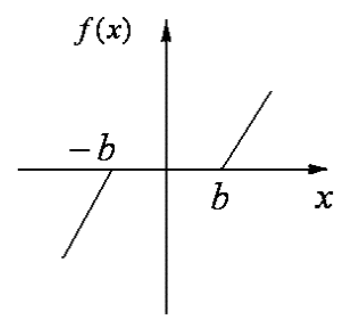

Fig. 3 Gear side clearance and force diagram

Then Eq. 1 is rewritten in non-dimensional form:

$$
\ddot{x}+2\left(\zeta+\zeta_{\Delta}\right) \dot{x}+\bar{k}(t) f(x)=F_{m}^{\prime}+\bar{F}_{h}(t)+F_{\Delta}^{\prime},
$$

where the non-dimensional quantities $\bar{F}_{h}(t)=F_{h}(t) / b_{e}$, $F_{m}^{\prime}=F_{m} / m_{e} b_{e} \omega_{n}^{2}, \quad F_{\Delta}^{\prime}=F_{\Delta} / m_{c 1} b_{e} \omega_{n}^{2}, \quad \zeta=c_{h} / 2 m_{e} \omega_{n}$, $\bar{k}(t)=k(t) / m_{e} \omega_{n}^{2}$ have been introduced. $F_{h}(t)$ is equivalent internal error excitation caused by gear integrated error. $F_{m}$ is gear equivalent external incentive.

If the stiffness and gear meshing error take the first-order harmonic component, there are:

$$
\begin{aligned}
& \bar{k}(t)=1+\varepsilon \cos \left(\left(\omega_{h}^{\prime}+\omega_{\Delta}^{\prime}\right) t+\phi_{h}\right) ; \\
& \bar{F}_{h}(t)=F_{a h 1} \omega_{h}^{2} \cos \left(\left(\omega_{h}^{\prime}+\omega_{\Delta}^{\prime}\right) t+\varphi_{h}\right),
\end{aligned}
$$

where the non-dimensional quantities $F_{a h 1}=e / b_{e}$, $\varepsilon=k_{a} / k_{a v}, \omega_{\Delta}^{\prime}=\omega_{\Delta} / \omega_{n}$ have been introduced. $e$ is dimensional error amplitude; $k_{a}$ is the time-varying meshing stiffness; $\omega_{\Delta}$ is the meshing frequency stochastic disturb- 
ance. Considering the relationship between meshing stiffness and meshing error, let meshing phase angle $\phi_{h}=\varphi_{h}+\pi, \varphi_{h}=0, \varphi_{h}$ is the variable stiffness initial phase.
Let $z_{1}=x, z_{2}=\dot{x}$, Then Eq. 2 is transformed into the state equation:

$$
\left.\begin{array}{l}
\dot{z}_{1}=z_{2} ; \\
\dot{z}_{2}=F_{m}^{\prime}+F_{a h 1}\left(\omega_{h}^{\prime}+\omega_{\Delta}^{\prime}\right)^{2} \cos \left(\left(\omega_{h}^{\prime}+\omega_{\Delta}^{\prime}\right) t\right)-2\left(\zeta+\zeta_{\Delta}\right) z_{2}-\left[1-\left(\varepsilon+\varepsilon_{\Delta}\right) \cos \left(\left(\omega_{h}^{\prime}+\omega_{\Delta}^{\prime}\right) t\right)\right] f\left(z_{1}\right)+F_{\Delta}^{\prime},
\end{array}\right\}
$$

where $\varepsilon_{\Delta}$ is the non-dimensional time-varying meshing stiffness stochastic disturbance, $\varepsilon_{\Delta}=k_{a \Delta} / k_{a v}, k_{a \Delta}$ is the timevarying meshing stiffness stochastic disturbance.

\section{Nonlinear dynamic analysis}

3.1. Influence of damping ratio on the system movement characteristics

The gear transmission system, with parameters $F_{m}^{\prime}=0.053, F_{a h 1}=0.1, \omega_{h}^{\prime}=1.2, \bar{b}=1.0, \varepsilon=0.09$, has been chosen to be analyzed. Non-dimensional stochastic perturbation $\omega_{\Delta}^{\prime}$ obeys normal distribution $N\left(0,0.000005^{2}\right)$, and in the range of $(-0.00002,0.00002)$. $\varepsilon_{\Delta}$ obey normal distribution $N\left(0,0.01^{2}\right)$, and in the range of $(-0.04,0.04) . F_{\Delta}^{\prime}$ and $\zeta_{\Delta}$ obey normal distribution $N\left(0,0.001^{2}\right)$, and in the range of $(-0.004,0.004)$. Stochastic variables meet $3 \sigma$ theory. Taken from the initial state $z_{1}(0)=0, z_{2}(0)=0$. Gear damping ratio $\zeta$ is taken as bifurcation parameters. Numerical simulation of the system is resolved by using a 4-5 order variable step-size Runge-Kutta numerical integration algorithm. So we can get the bifurcation and Poincaré diagrams of system in Fig. 4 and Fig. 5.
In conjunction with Fig. 4 and Fig. 5, we can see that with the bifurcation parameter $\zeta$ increasing, the motion system first is chaotic motion. Under different gear damping ratio $\zeta=0.001,0.02,0.06$ and 0.1 , chaotic attractor is not the same shape, as shown in Fig. 5, a-d. When $\zeta=0.128$, the gear system will be from chaotic motion to periodic 2 motion with a noisy disturbance through inverse period doubling bifurcation. Taken $\zeta=0.2$, the Poincaré map of the system is shown in Fig. 5, e. With the bifurcation parameter $\zeta$ increasing, as $\zeta=0.218$, the gear system will be from periodic 2 motion to periodic 1 motion with a noisy disturbance through inverse period doubling bifurcation. Taken $\zeta=0.25$, the Poincare map of the system is shown in Fig. 5, f.

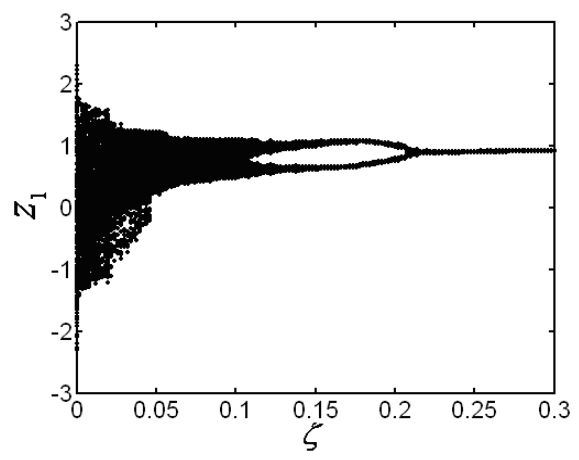

Fig. 4 Bifurcation diagram of the system with stochastic perturbation

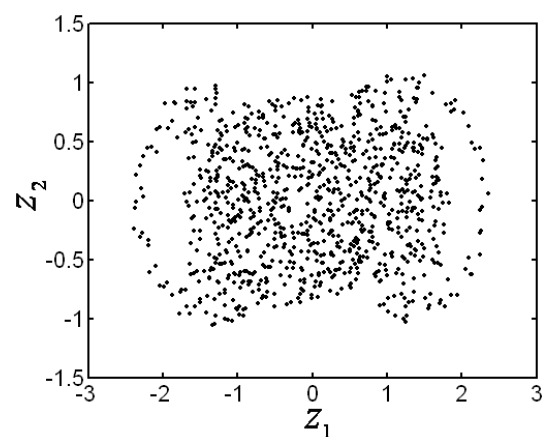

a

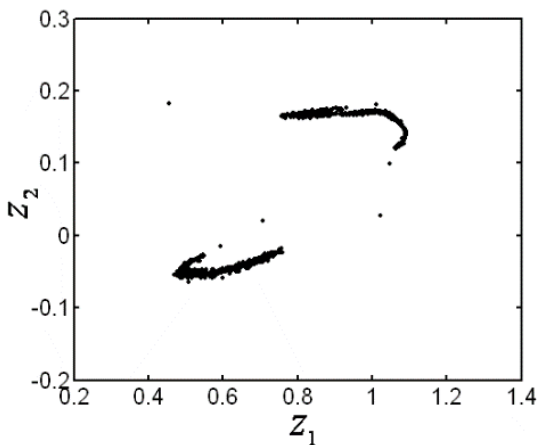

d

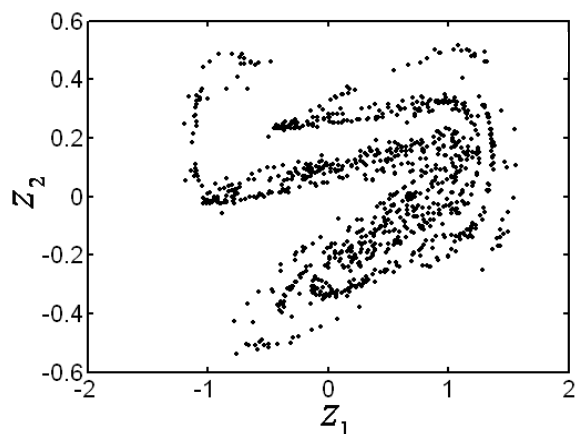

b

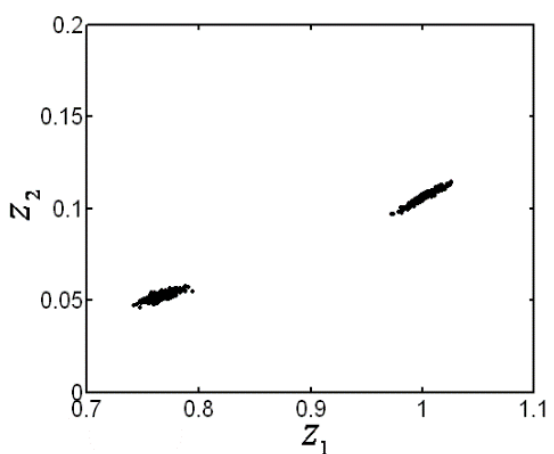

e

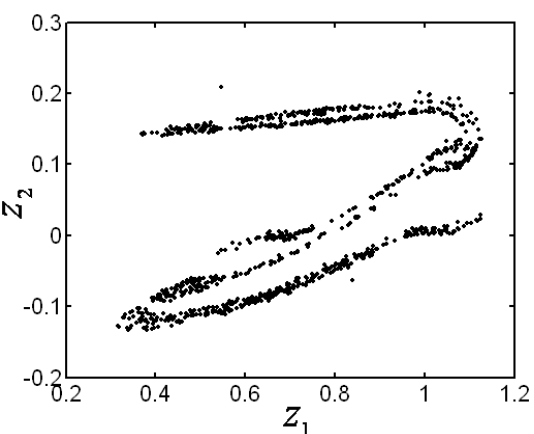

c

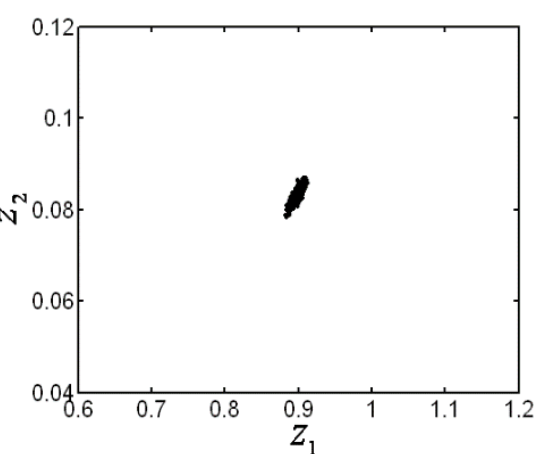

f

Fig. 5 Poincaré map of the system for different $\zeta$ values: a $-\zeta=0.001$, chaos; $\mathrm{b}-\zeta=0.02$, chaos; $\mathrm{c}-\zeta=0.06$, chaos; $\mathrm{d}-\zeta=0.1$, chaos; e $-\zeta=0.2$, period $2 ; \mathrm{f}-\zeta=0.25$, period 1 
3.2. Influence of meshing stiffness on the system movement characteristics

Let $F_{m}^{\prime}=0.063, F_{a h 1}=0.02, \omega_{h}^{\prime}=1.2, \bar{b}=1.0$, $\zeta=0.34$. Non-dimensional stochastic perturbation $\omega_{\Delta}^{\prime}$ obeys normal distribution $N\left(0,0.000005^{2}\right)$, and in the range of $(-0.00002,0.00002) . \varepsilon_{\Delta}$ and $\zeta_{\Delta}$ obey normal distribution $N\left(0,0.01^{2}\right)$, and in the range of $(-0.04,0.04)$. $F_{\Delta}^{\prime}$ obey normal distribution $N\left(0,0.001^{2}\right)$, and in the range of $(-0.004,0.004)$. Stochastic variables meet $3 \sigma$ theory. Taken the initial state $z_{1}(0)=0, z_{2}(0)=0$. The meshing stiffness $\varepsilon$ is taken as bifurcation parameters. Numerical simulation of the system is resolved by using a 4-5 order variable step-size Runge-Kutta numerical integration algorithm. So we can obtain the bifurcation and Poincaré diagrams of the system in Fig. 6 and Fig. 7.

From Fig. 6 and Fig. 7, we can see that with the bifurcation parameter $\varepsilon$ increasing, the motion system first is periodic 1 motion with a noisy disturbance. Taken $\varepsilon=1.7$, the Poincare map of system is shown in Fig. 7, a. With the

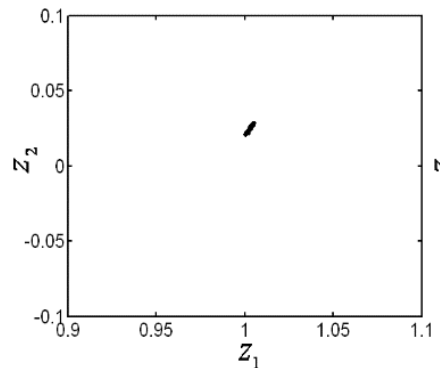

a

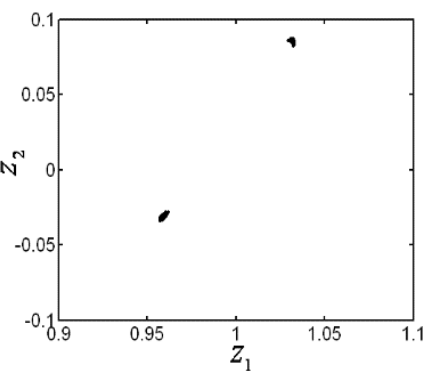

b

Fig. 7 Poincaré map of the system for different $\varepsilon$ values: a $-\varepsilon=1.7$, period $1 ; \mathrm{b}-\varepsilon=2.0$, period 2 ; c $-\varepsilon=2.28$, chaos; $\mathrm{d}-\varepsilon=2.51$, chaos

\subsection{Influence of meshing frequency on the system} movement characteristics

The gear transmission system, with parameters $F_{m}^{\prime}=0.05, F_{a h 1}=0.05, \varepsilon=0.08, \zeta=0.04, \bar{b}=1.0$, has been chosen to be analyzed. Dimensional stochastic perturbation $\omega_{\Delta}^{\prime}$ obeys normal distribution $N\left(0,0.000005^{2}\right)$, and in the range of $(-0.00002,0.00002) . \varepsilon_{\Delta}$ and $\zeta_{\Delta}$ obey normal $F_{\Delta}^{\prime}$ distribution $N\left(0,0.01^{2}\right)$, and in the range of $(-0.04,0.04)$ obey normal distribution $N\left(0,0.001^{2}\right)$, and in the range of $(-0.004,0.004)$. Stochastic variables meet $3 \sigma$ theory. The meshing frequency $\omega$ is taken as the bifurcation parameter. Supposing the initial point of the system is $z_{1}(0)=0, z_{2}(0)=0$. We applied 4-5 order variable step-size Runge-Kutta method to the numerical simulation of the gear transmission system, the bifurcation and Poincaré diagrams of the system is illustrated in Fig. 8 and Fig. 9.

Seen from Fig. 8 and Fig. 9, with the bifurcation parameter $\omega$ increasing, the motion system first is periodic 1 motion.

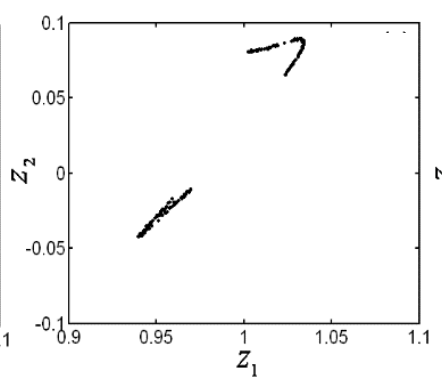

c

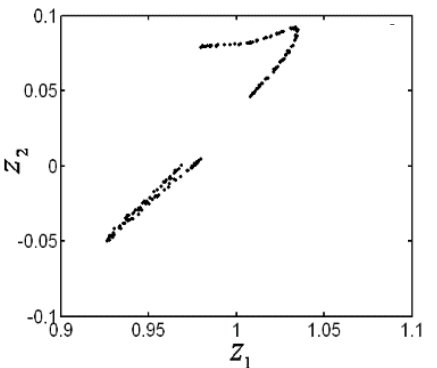

d bifurcation parameter $\varepsilon$ increasing, as $\varepsilon=1.885$, the gear system will be from periodic 1 motion to periodic 2 motion with a noisy disturbance through Hopf bifurcation. Taken $\varepsilon=2.0$, the Poincaré map of the system is shown in Fig. 7, b. When $\varepsilon=2.065$, the gear system will be from periodic 1 motion to chaotic motion. Taken $\varepsilon=2.28$ and 2.51, the Poincaré map of the system is shown in Fig. 7, c and Fig. 7, d, which are two similar types of chaotic attractors.

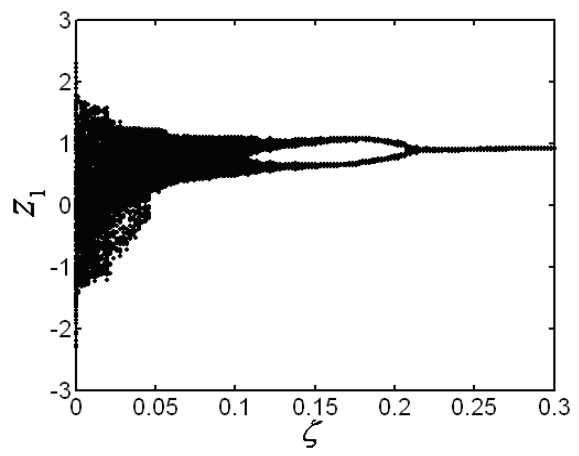

Fig. 6 Bifurcation diagram of the system with stochastic perturbation

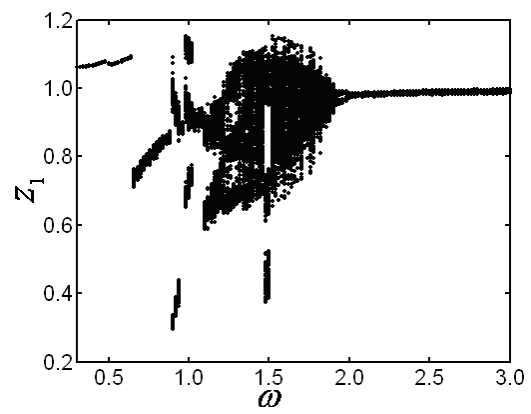

Fig. 8 Bifurcation diagram of the system with stochastic perturbation

Taken $\omega=0.2$, the Poincare map of the system is shown in Fig. 9, a. When $\omega=0.9$, the gear system will be from periodic 1 motion to periodic 2 motion with a noisy disturbance through period doubling bifurcation. Taken $\omega=0.92$, the Poincare map of the system is shown in Fig. 9, b. When $\omega=1.04$, the gear system will be from periodic 2 motion to periodic 1 motion by inverse period doubling bifurcation. Taken $\omega=1.06$, the Poincare map of the system is shown in Fig. 9, c. When $\omega=1.10$, the gear system will be again from periodic 1 motion to periodic 2 motion through period doubling bifurcation. Taken $\omega=1.2$, the Poincare map of the system is shown in Fig. 9, d. With the 
bifurcation parameter $\omega$ increasing, as $\omega=1.40$, the gear system will be from periodic 2 motion to chaotic motion. Taken $\omega=1.42$, the Poincaré map of the system is shown in Fig. 9, e. When $\omega=1.92$, the gear system will be from chaotic motion to periodic 2 motion. Taken $\omega=1.94$, the Poincaré map of the system is shown in Fig. 9, f. As $\omega=2.0$, the gear system will be from periodic 2 motion to periodic 1 motion. Taken $\omega=2.10$, the Poincaré map of the system is shown in Fig. 9, g. In the Fig. 9, b, Fig. 9, c, Fig. 9, d, Fig. 9, f and Fig. 9, g, Poincaré maps are point set due to stochastic perturbation parameters.

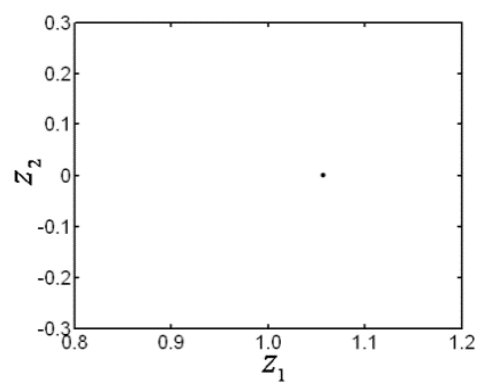

a

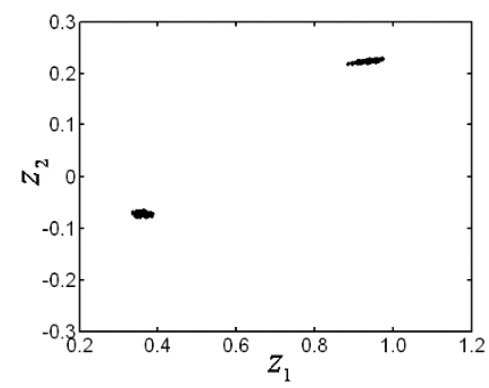

b

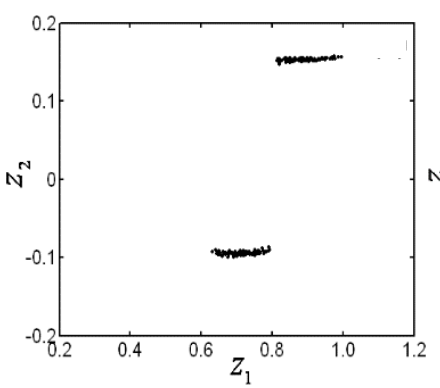

d

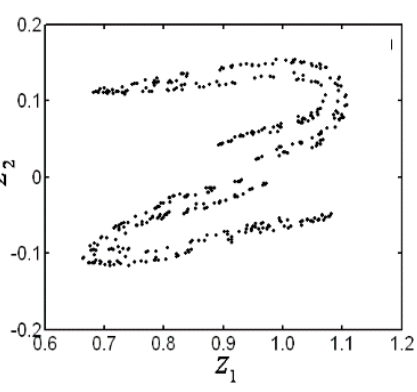

$\mathrm{e}$

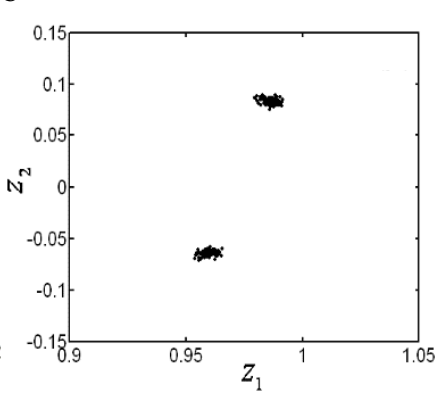

$\mathrm{f}$

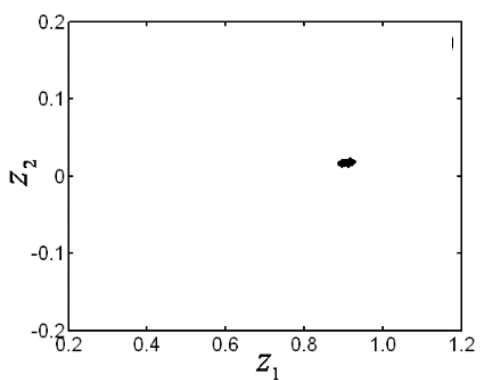

C

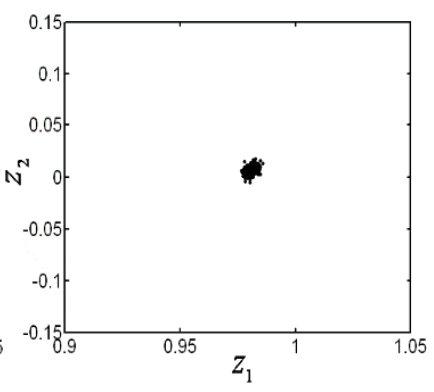

$\mathrm{g}$

Fig. 9 Poincaré map of the system for different $\varepsilon$ values: a $-\varepsilon=1.7$, period $1 ; \mathrm{b}-\varepsilon=2.0$, period 2 ; c $-\varepsilon=2.28$, chaos; $\mathrm{d}-\varepsilon=2.51$, chaos

\section{Chaos control}

\subsection{Feedback control}

\subsubsection{Linear control method}

The $n$ dimensional system is:

$$
\dot{X}=F(X(t), t) ; y=K X \text {. }
$$

In the formula, $X$ is the state variable of $n$ dimension system, $X=\left[x_{1}, x_{2}, \cdots, x_{n}\right]^{T}, K$ is a $1 \times n$ constant ma- trix. $F$ is a smooth nonlinear vector function. $y$ is the output of the system. The linear feedback controller of the system is $W=G\left(y_{1}-y_{2}\right) . G$ is the feedback gain matrix. Then, the controlled system is:

$$
\dot{X}=F(X(x), t)-W .
$$

In the gear transmission system, if $G=[g, 0]^{T}, g$ is the control parameter, $z$ is the system output, the equation of the controlled system is:

$$
\left.\begin{array}{l}
\dot{z}_{1}=z_{2}-g\left(z_{1}-z_{2}\right) ; \\
\dot{z}_{2}=F_{m}^{\prime}+F_{a h 1}\left(\omega_{h}^{\prime}+\omega_{\Delta}^{\prime}\right)^{2} \cos \left(\left(\omega_{h}^{\prime}+\omega_{\Delta}^{\prime}\right) t\right)-2\left(\zeta+\zeta_{\Delta}\right) z_{2}-\left[1-\left(\varepsilon+\varepsilon_{\Delta}\right) \cos \left(\omega_{h}^{\prime}+\omega_{\Delta}^{\prime}\right) t\right] f\left(z_{1}\right)+F_{\Delta}^{\prime} \cdot
\end{array}\right\}
$$

By the analysis of Fig. 5, when $\zeta=0.02$, the system appears chaos. By introducing the linear feedback controller control, the other parameters unchanged, using 4-5 order variable step Runge-Kutta method to carry on numerical simulation, and to get he bifurcation diagram of the controlled system, as shown in Fig. 10. By selecting different control parameter, the chaotic motion of the system can be suppressed to different periodic orbits. When $g \in$ $(0,0.53)$, the system is suppressed to the periodic 2 motion with a noisy disturbance. Taken $g=0.5$, the phase portrait, time course diagram and the Poincaré map of the controlled system are shown in Fig. 11. When $g>0.53$, the system is suppressed to periodic 1 motion with a noisy disturbance. Take $g=0.8$, the phase portrait, time course diagram and the Poincare map of the controlled system are shown in Fig. 12.

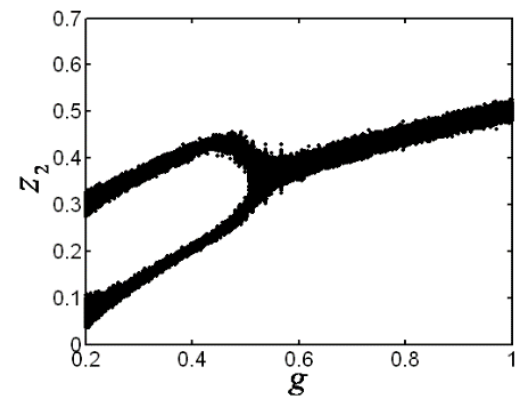

Fig. 10 Bifurcation diagram of the controlled system 


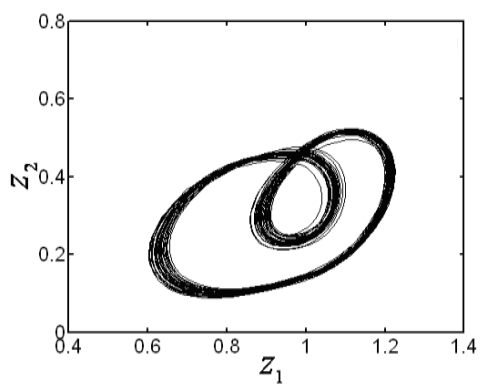

a

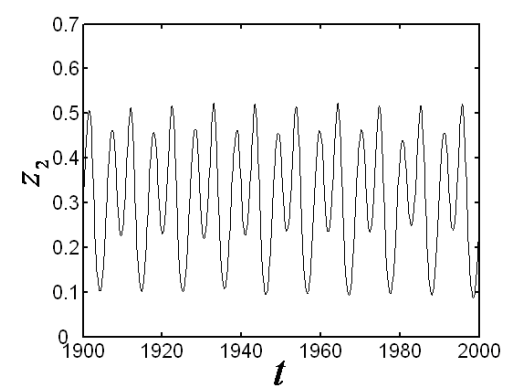

$\mathrm{b}$

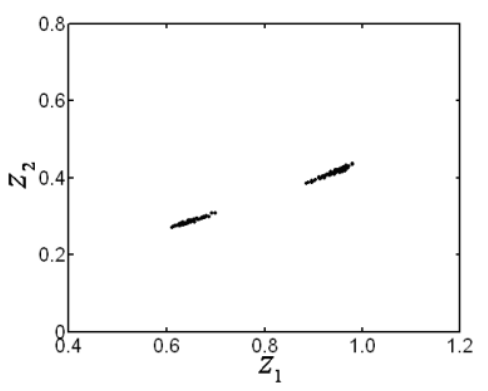

c

Fig. 11 a - Phase portrait; b - time course diagram; c - poincaré map of the controlled system $(g=0.5)$

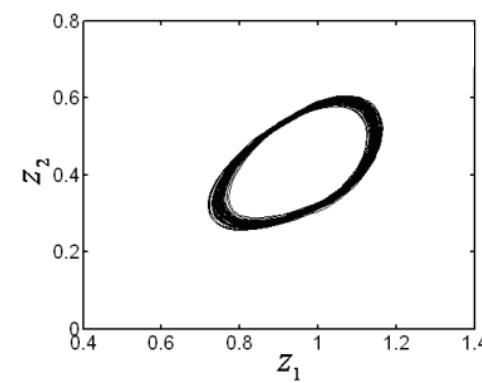

a

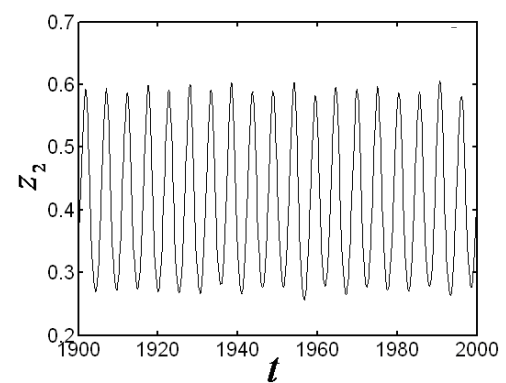

b

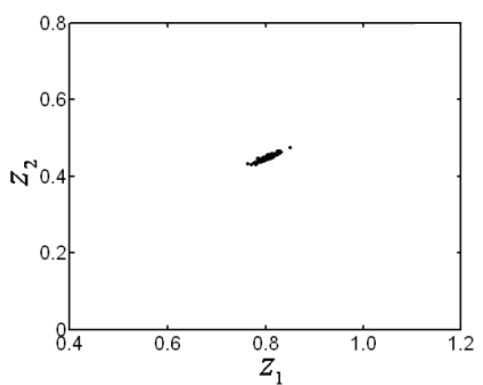

c

Fig. 12 a - Phase portrait; b - time course diagram; c - poincaré map of the controlled system $(g=0.8)$

\subsubsection{Nonlinear control method}

The definition of an n-dimensional non-linear chaotic system is as follows:

$$
\left\{\begin{array}{l}
\dot{x}=F(X(t), t) ; \\
\dot{y}=D X
\end{array}\right.
$$

where, $F$ is a smooth nonlinear vector function, $X$ is system state variable, $X=\left[x_{1}, x_{2}, \ldots, x_{n}\right]^{T} . y$ is the output of the system. The constant matrix $D$ is $1 \times n$. The nonlinear feedback controller of the system is $U=K y|y|$. Where $K$ is a feedback gain matrix. The nonlinear feedback controller is supplemented by the system. Then the controlled system is:

$$
\dot{x}=F(X(x), t)-U \text {. }
$$

If $K=[k, 0]^{T}, z$ is the system output, the equation of the controlled system is:

$$
\left.\begin{array}{l}
\dot{z}_{1}=z_{2}-k z_{1}\left|z_{1}\right| \\
\dot{z}_{2}=F_{m}^{\prime}+F_{a h 1}\left(\omega_{h}^{\prime}+\omega_{\Delta}^{\prime}\right)^{2} \cos \left(\left(\omega_{h}^{\prime}+\omega_{\Delta}^{\prime}\right) t\right)-2\left(\zeta+\zeta_{\Delta}\right) z_{2}-\left[1-\left(\varepsilon+\varepsilon_{\Delta}\right) \cos \left(\omega_{h}^{\prime}+\omega_{\Delta}^{\prime}\right) t\right] f\left(z_{1}\right)+F_{\Delta}^{\prime} \cdot
\end{array}\right\}
$$

From the Fig. 7, we can see that when $\varepsilon=2.51$, the system is chaotic vibration. By introducing the nonlinear feedback controller, using 4-5 order variable step RungeKutta method to carry on the numerical simulation, the bifurcation diagram of the control system is shown in Fig. 13. By selecting different control parameter, the chaotic motion of the system is well controlled to the stable periodic orbits. Taken $k=0.04$, the system will be controlled to the periodic 2 motion with a noisy disturbance, which the phase portrait, time course diagram and Poincaré map of the controlled system are shown in Fig. 14.

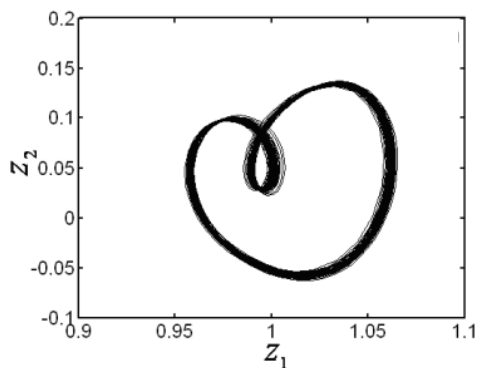

a

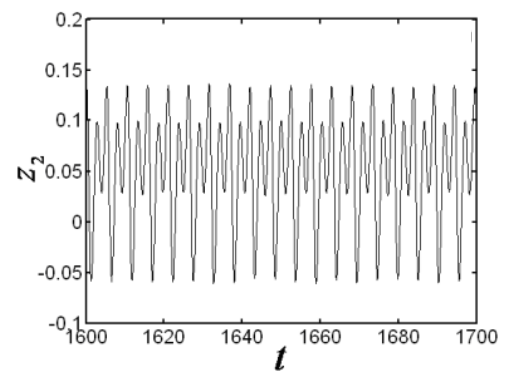

b

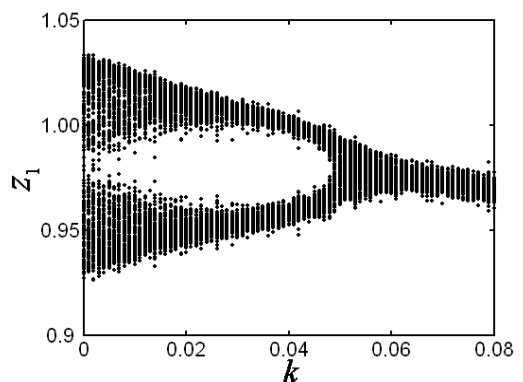

Fig. 13 Bifurcation diagram of the controlled system

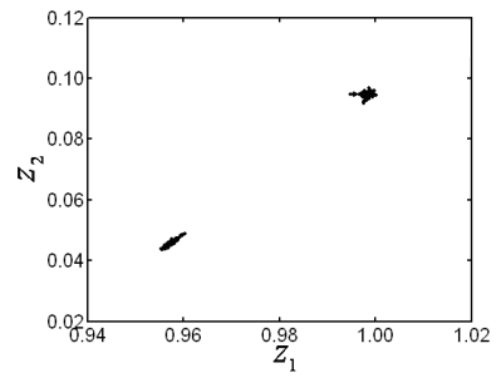

c

Fig. 14 a - Phase portrait; $\mathrm{b}$ - time course diagram; c - poincaré map of the system $(k=0.04)$ 
Taken $k=0.07$, the system will be controlled to the periodic 1 motion with a noisy disturbance, which the phase portrait, time course diagram and Poincaré map of the controlled system are shown in Fig. 15.

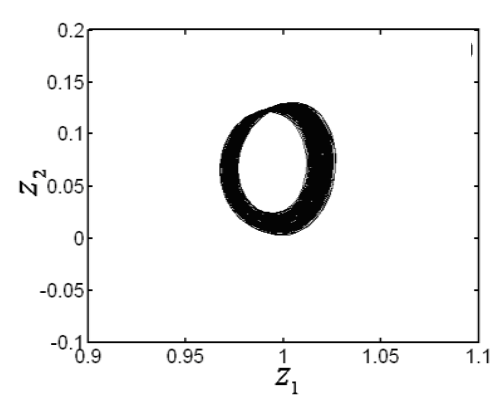

a

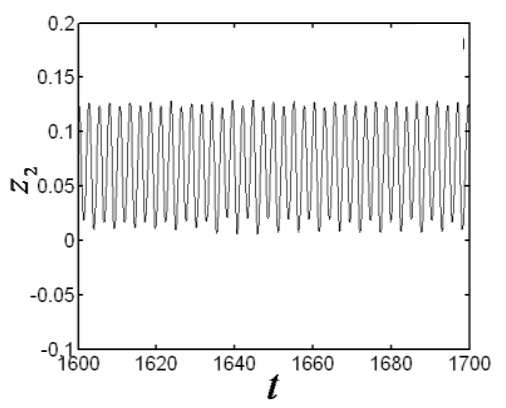

b

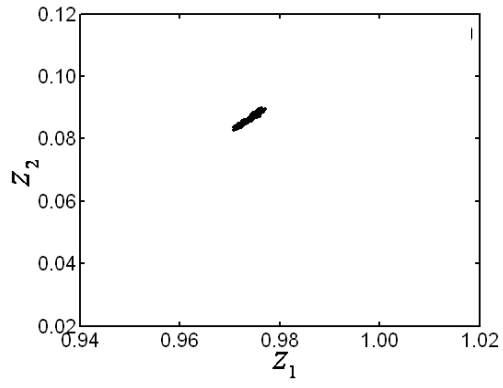

$\mathrm{c}$

Fig. 15 a - Phase portrait; b - time course diagram; c - poincaré map of the system $(k=0.07)$

\subsection{Non-feedback control}

\subsubsection{Periodic signal method}

A periodic signal as a driving force in the state equations, the controlled equation of the system is:

$$
\left.\begin{array}{l}
\dot{z}_{1}=z_{2} ; \\
\dot{z}_{2}=F_{m}^{\prime}+F_{a h 1}\left(\omega_{h}^{\prime}+\omega_{\Delta}^{\prime}\right)^{2} \cos \left(\left(\omega_{h}^{\prime}+\omega_{\Delta}^{\prime}\right) t\right)-2\left(\zeta+\zeta_{\Delta}\right) z_{2}-\left[1-\left(\varepsilon+\varepsilon_{\Delta}\right) \cos \left(\omega_{h}^{\prime}+\omega_{\Delta}^{\prime}\right) t\right] f\left(z_{1}\right)+F_{\Delta}^{\prime}-k \cos \left(\omega_{1} t\right) .
\end{array}\right\}
$$

From the above Fig. 8 , when $\omega=1.8$, the initial movement of the system is chaotic motion. By introducing the periodic signal method, using 4-5 order variable step Runge Kutta method to carry on the numerical simulation, the bifurcation diagram of the control system is illustrated in Fig. 16. When $\omega=1.8$ and $k=0.26$, the system is controlled to be stable periodic 2 motion with a noisy disturbance. The phase portrait, time course diagram and Poincaré map of the controlled system are shown in Fig. 17. While $\omega_{1}=1.8$ and $k=1.5$, the system is controlled to be stable periodic 1 motion with a noisy disturbance. The phase portrait, time course diagram and Poincaré map of the controlled system are shown in Fig. 18.

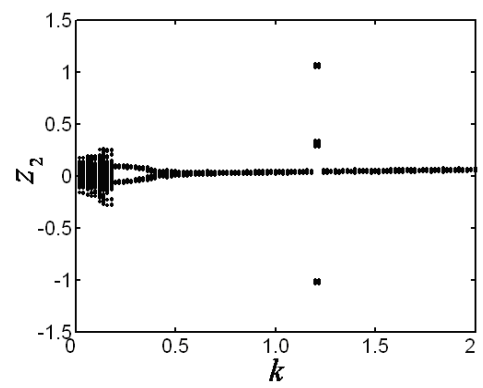

Fig. 16 Bifurcation diagram of the controlled system

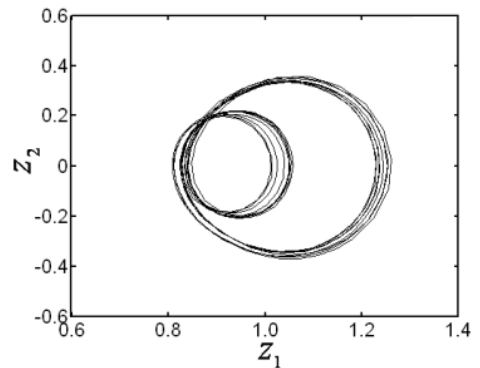

a

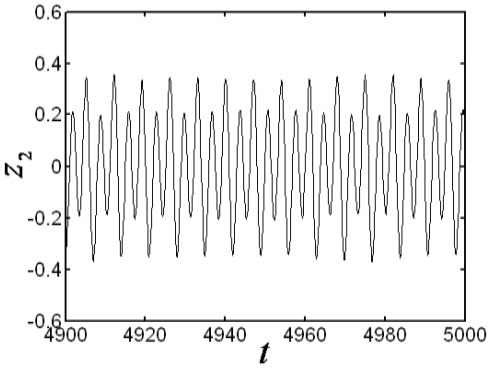

b

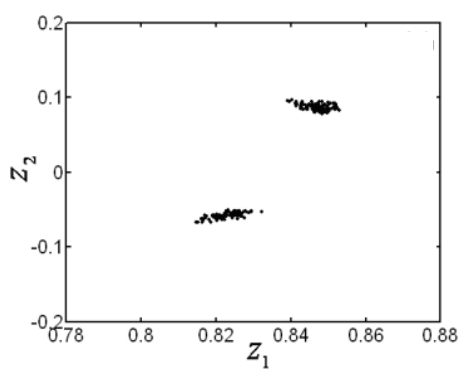

c

Fig. 17 a - Phase portrait; b - time course diagram; c - poincaré map of the controlled system with stochastic perturbation $(k=0.26)$

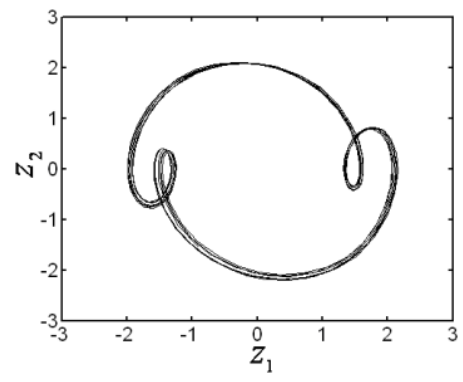

a

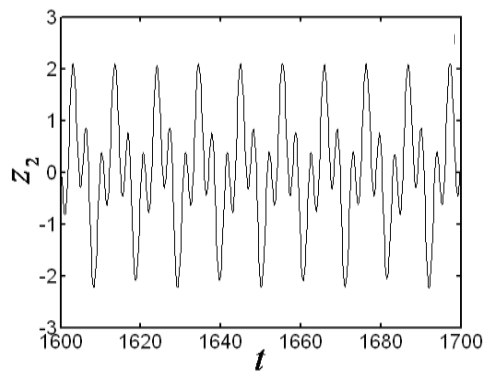

b

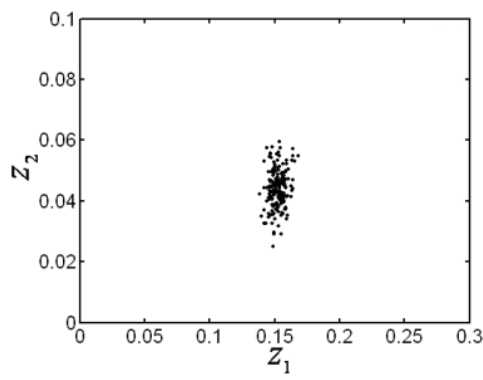

c

Fig. 18 a - Phase portrait; b - time course diagram; c - poincaré map of the controlled system with stochastic perturbation $(k=1.5)$ 


\subsubsection{Plus a constant load method}

A constant load applied on the state equation, the controlled equation of the system is

$$
\left.\begin{array}{l}
\dot{z}_{1}=z_{2} \\
\dot{z}_{2}=F_{m}^{\prime}+F_{a h 1}\left(\omega_{h}^{\prime}+\omega_{\Delta}^{\prime}\right)^{2} \cos \left(\left(\omega_{h}^{\prime}+\omega_{\Delta}^{\prime}\right) t\right)-2\left(\zeta+\zeta_{\Delta}\right) z_{2}-\left[1-\left(\varepsilon+\varepsilon_{\Delta}\right) \cos \left(\omega_{h}^{\prime}+\omega_{\Delta}^{\prime}\right) t\right] f\left(z_{1}\right)+F_{\Delta}^{\prime}-F .
\end{array}\right\}
$$

Seen from Fig. 8, when $\omega=1.8$, the initial movement of the system is chaotic motion. By introducing the plus a constant load method, using 4-5 order variable step Runge-Kutta method to carry on the numerical simulation, the bifurcation diagram of the control system is illustrated in Fig. 19. As $F=0.06$, the system is controlled to be stable periodic 2 motion with a noisy disturbance. The phase portrait, time course diagram and Poincaré map of the controlled system are shown in Fig. 20. While $F=0.6$, the system is controlled to be stable periodic 1 motion with a noisy disturbance. The phase portrait, time course diagram and Poincaré map of the controlled system are shown in Fig. 21.

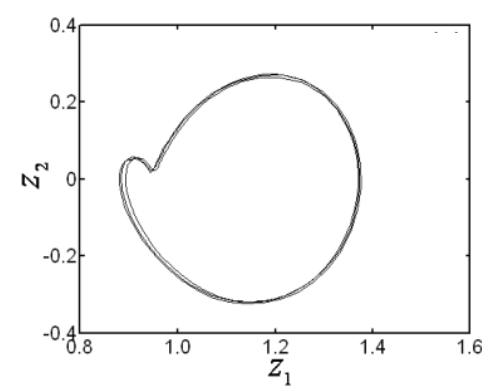

a

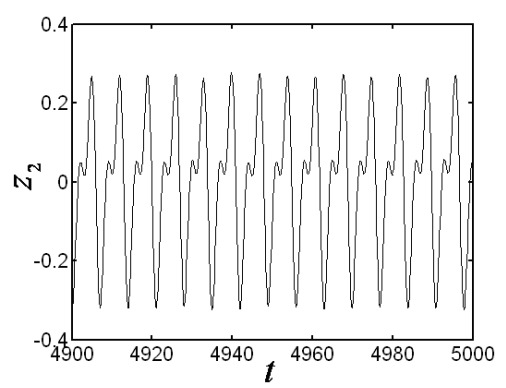

b

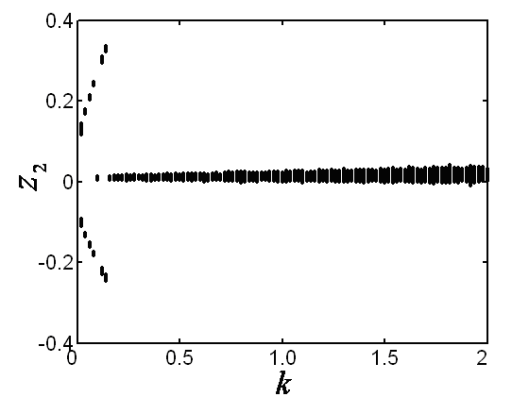

Fig. 19 Bifurcation diagram of the controlled system

Fig. 20 a - Phase portrait; b - time course diagram; c - poincaré map of the controlled system with stochastic perturbation $(F=0.06)$

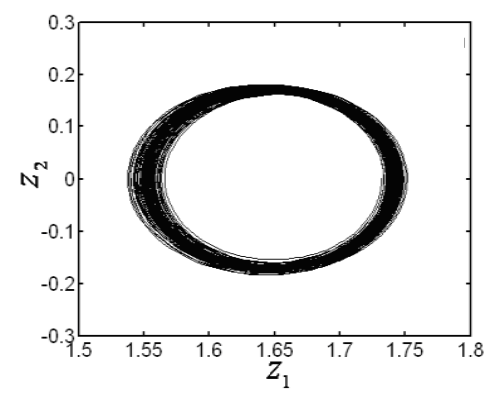

a

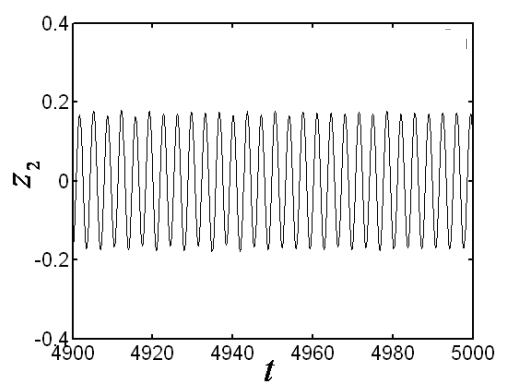

$\mathrm{b}$

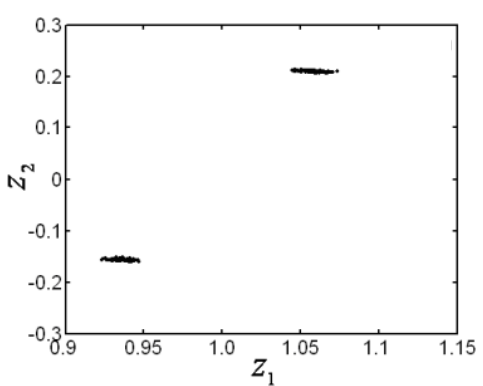

c

Fig. 21 a - Phase portrait; b - time course diagram; c - poincaré map of the controlled system with stochastic perturbation $(F=0.6)$

\subsubsection{Phase method}

The periodic signal with phase different from the

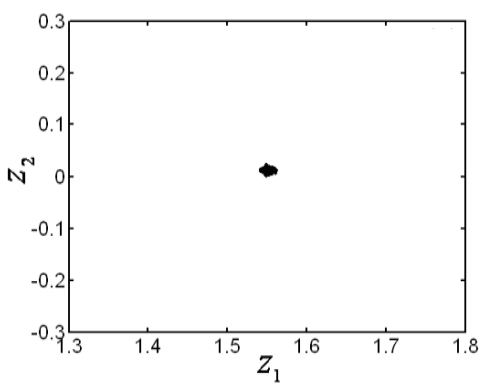

c

original signal is as a driving force in the state equations of the system. Thus, the control equation of the system is:

$$
\left.\begin{array}{l}
\dot{z}_{1}=z_{2} ; \\
\dot{z}_{2}=F_{m}^{\prime}+F_{a h 1}\left(\omega_{h}^{\prime}+\omega_{\Delta}^{\prime}\right)^{2} \cos \left(\left(\omega_{h}^{\prime}+\omega_{\Delta}^{\prime}\right) t\right)-2\left(\zeta+\zeta_{\Delta}\right) z_{2}-\left[1-\left(\varepsilon+\varepsilon_{\Delta}\right) \cos \left(\omega_{h}^{\prime}+\omega_{\Delta}^{\prime}\right) t\right] f\left(z_{1}\right)+F_{\Delta}^{\prime}-k \cos \left(\omega_{2} t+\phi\right) .
\end{array}\right\}
$$

In the same way, seen from Fig. 8 , when $\omega=1.8$, the initial movement of the system is chaotic motion. By introducing the phase method, using 4-5 order variable step Runge Kutta method to carry on the numerical simulation, the bifurcation diagram of the control system with $k=1.2$, $\omega_{2}=1.8,0.9$ and $0.6, \varphi=10$ are shown in Fig. 22. In
Fig. 22, a, taken $\omega_{2}=1.8$ the system is controlled to be stable periodic 1 motion with a noisy disturbance. The phase portrait, time course diagram and Poincaré map of the controlled system are shown in Fig. 23. In Fig. 22, b, taken $\omega_{2}=0.9$, the system is controlled to be stable periodic 2 motion with a noisy disturbance. The phase portrait, time 
course diagram and Poincaré map of the controlled system are shown in Fig. 24. In Fig. 22, c, taken $\omega_{2}=0.6$, the system is controlled to be stable periodic 3 motion with a noisy disturbance. The phase portrait, time course diagram and Poincaré map of the controlled system are shown in Fig. 25.

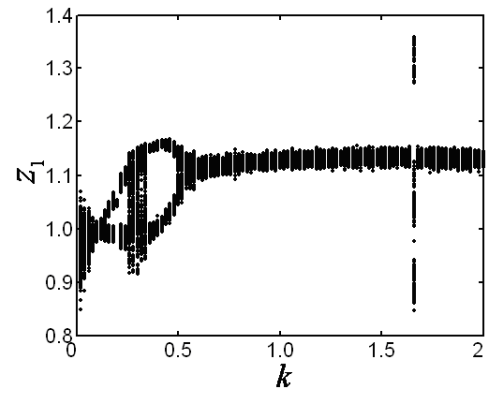

$\mathrm{a}$

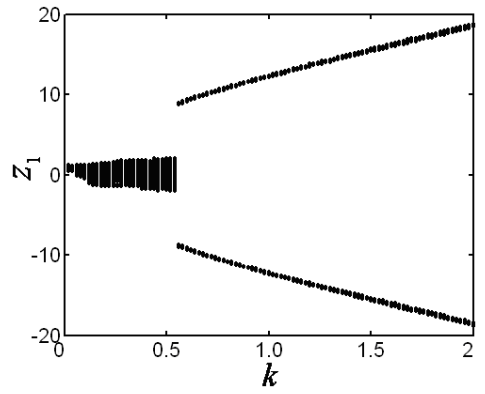

$\mathrm{b}$

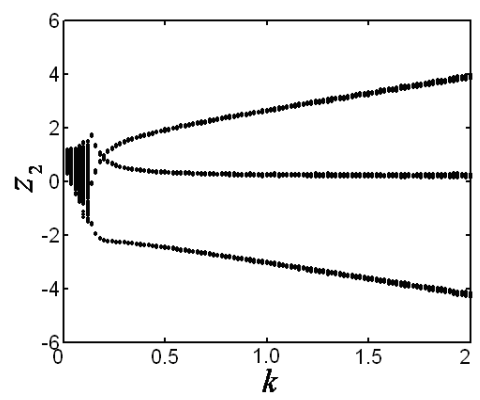

c

Fig. 22 Bifurcation diagram of the controlled system

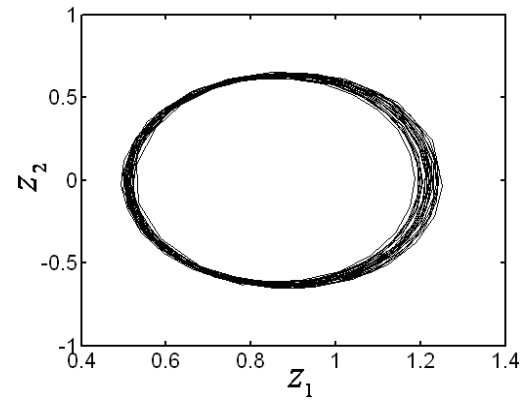

a

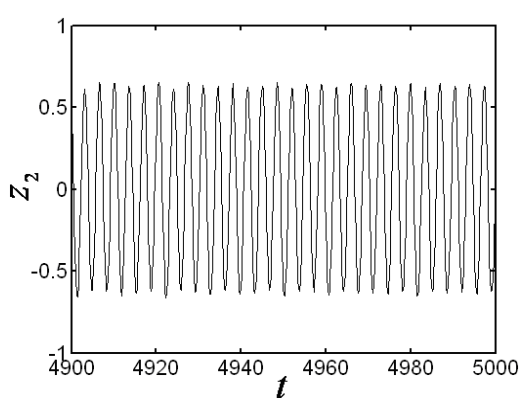

b

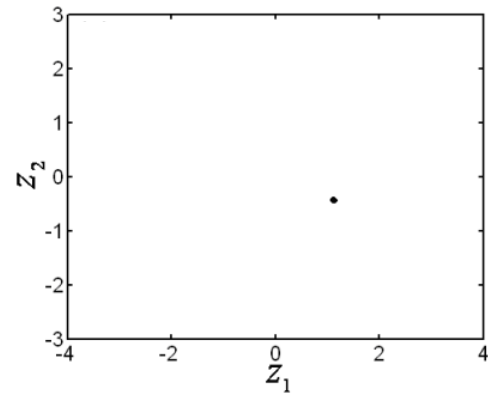

c

Fig. 23 a - Phase portrait; b - time course diagram; c - poincaré map of the controlled system with stochastic perturbation $\left(k=1.2, \omega_{2}=1.8, \varphi=10\right)$

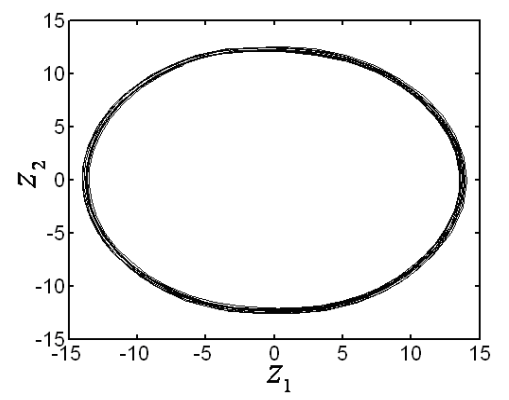

a

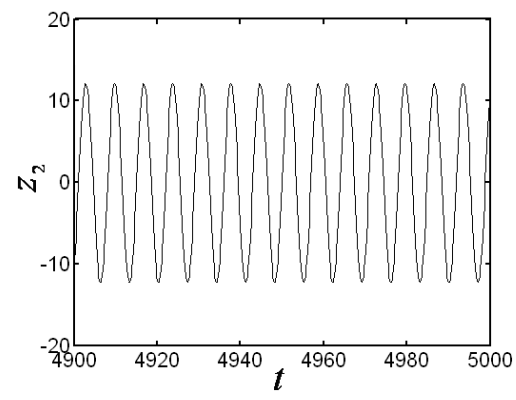

$\mathrm{b}$

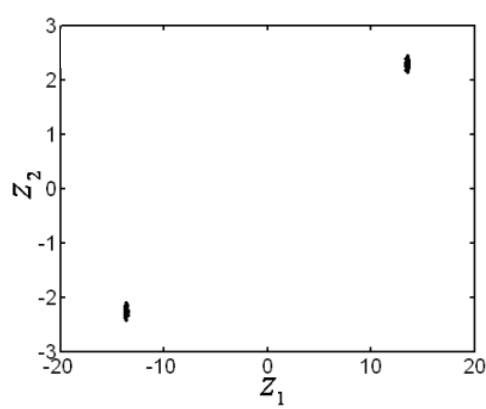

c

Fig. 24 a - Phase portrait; b - time course diagram; c - poincaré map of the controlled system with stochastic perturbation $\left(k=1.2, \omega_{2}=0.9, \varphi=10\right)$

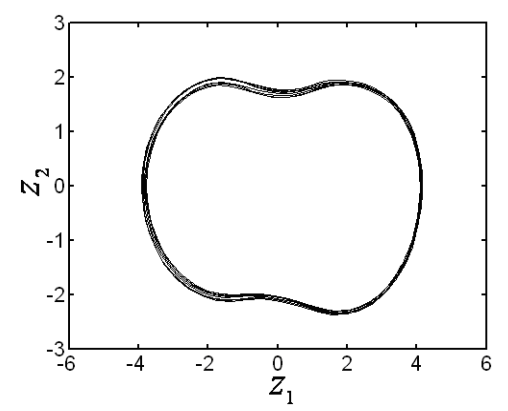

a

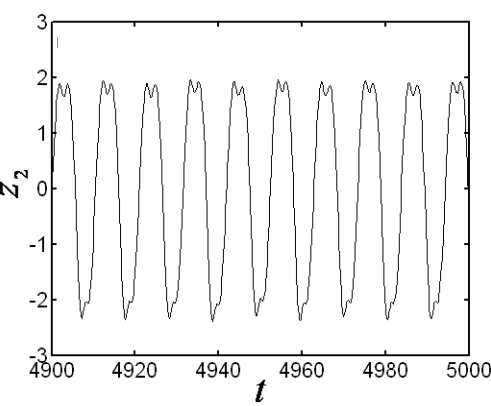

b

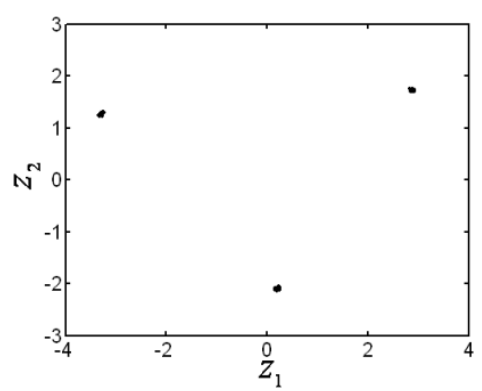

c

Fig. 25 a - Phase portrait; b - time course diagram; c - poincaré map of the controlled system with stochastic perturbation $\left(k=1.2, \omega_{2}=0.6, \varphi=10\right)$ 


\section{Conclusions}

In the paper, considering stochastic perturbation of gear backlash, gear damping ratio, meshing frequency meshing stiffness and input torque fluctuation, a single degree of freedom spur gear transmission system mechanics model and dynamical equations are established according to the Newton's rule. Utilizing 4-5 order variable step-size Runge-Kutta algorithm, the differential equations of motion of the gear transmission system are solved numerically. Nonlinear dynamic characteristics especially bifurcation and chaos are analyzed respectively with mesh, mesh stiffness, damping ratio and frequency changing. In order to control the chaotic vibration in gear transmission system occurs, the article has the use of feedback control of linear and nonlinear, as well as three kinds of non-feedback control of the applied periodic signal method, a constant load method and phase method for the suppression of chaotic motion to the stable periodic orbits. In the subsequent study, we will use the experiments to verify the validity of such methods, and popularize these methods to the higher dimensional systems.

\section{Acknowledgements}

The authors gratefully acknowledge the support of programs for the Natural Science Foundation of Liaoning Province of China (20170540786), the State Key Laboratory of Mechanical Transmissions (SKLMT-KFKT201605), the Open Foundation of Key Discipline of Mechanical Design and Theory of Shenyang Ligong University (4771004kfx08), the Science and Technology Research Projects of Education Department of Liaoning Province of China (L2012068) and the National Natural Science Foundation of China (51275082).

\section{References}

1. De Souza, S.L.T.; Caldas, I.L. 2004. Sudden changes in chaotic attractors and transient basins in a model for rattling in gearboxes, Chaos, Solitons and Fractals 21(3): 763-772.

http://dx.doi.org/10.1016/j.chaos.2003.12.096.

2. Luo, A.C.J.; O'Connor. D. 2009. Periodic motions and chaos with impacting chatter and stick in a gear transmission system, International Journal of Bifurcation and Chaos 19(6): 1975-1994. http://dx.doi.org/10.1142/S0218127409023858.

3. Chang-Jian, C.W. 2010. Strong nonlinearity analysis for gear-bearing system under nonlinear suspension-bifurcation and chaos, Nonlinear Analysis: Real World Applications 11(3): 1760-1774. http://dx.doi.org/10.1016/j.nonrwa.2009.03.027.

4. Byrtus, M.; Zeman, V. 2011. On modeling and vibration of gear drives influenced by nonlinear couplings, Mechanism and Machine Theory 46(3): 375-397. http://dx.doi.org/10.1016/j.mechmachtheory.2010.10.007.

5. Kahranman, A.; Singh, R. 1990. Non-linear dynamics of a spur gear pair, Journal of Sound and Vibration142(1): 49-75. http://dx.doi.org/10.1016/0022-460X(90)90582-K.

6. Kahraman, A.; Singh, R. 1991. Nonlinear dynamics of a geared rotor-bearing system with multiple clearances, Journal of Sound and Vibration 144(3): 469-506. http://dx.doi.org/10.1016/0022-460X(91)90564-Z.

7. Kahranman, A.; Singh, R. 1991. Interactions between time-varying mesh stiffness and clearance non-linearities in a geared system, Journal of Sound and Vibration 146(1): 135-156. http://dx.doi.org/10.1016/0022-460X(91)90527-Q.

8. Theodossiades, S. 2000. Non-linear dynamics of gearpair systems with periodic stiffness and backlash, Journal of Sound and Vibration 229(2): 287-310.

http://dx.doi.org/10.1006/jsvi.1999.2490.

9. Theodossiades, S.; Natsiavas, S. 2001. Periodic and chaotic dynamics of motor-driven gear-pair systems with backlash, Chaos Solitons \& Fractals 12(13): 2427 2440. http://dx.doi.org/10.1016/S0960-0779(00)00210-1.

10. Huang, K.J.; Liu, T.S. 2000. Dynamic analysis of a spur gear by the dynamic stiffness method, Journal of Sound and Vibration 234(2): 311-329. http://dx.doi.org/10.1006/jsvi.1999.2869.

11. Howard, I.; Jia, S.; Wang, J. 2001. The dynamic modeling of a spur gear in mesh including friction and a crack, Mechanical Systems and Signal Processing 15(5): 831-853.

http://dx.doi.org/10.1006/mssp.2001.1414.

12. Shyyaba, A.; Kahraman, A. 2005. Non-linear dynamic analysis of a multi-mesh gear train using multi-term harmonic balance method: sub-harmonic motions, Journal of Sound and Vibration 279(1-2): 417-451. http://dx.doi.org/10.1016/j.jsv.2003.11.029.

13. Litak, G.; Friswell, M.I. 2005. Dynamic of a gear system with faults in meshing stiffness, Nonlinear Dynamics 41(4): 415-421. http://dx.doi.org/10.1007/s11071-005-1398-y.

14. Parey, A.; Badaoui, M.E.; Guillet F.; et al. 2006. Dynamic modeling of spur gear pair and application of empirical mode decomposition-based statistical analysis for early detection of localized tooth defect, Journal of Sound and Vibration 294(3): 547-561. http://dx.doi.org/10.1016/j.jsv.2005.11.021.

15. Eritenel, T.; Parker, R.G. 2009. Computational nonlinear vibration analysis of gear pairs using a three dimensional Model, ASME 2009 International Design Engineering Technical Conferences and Computers and Informationin Engineering Conference, SanDiego, CA, USA: $149-165$. http://dx.doi.org/10.1115/DETC2009-87485.

16. Bonori, G.; Pellicano, F. 2007. Non-smooth dynamics of spur gears with manufacturing errors, Journal of Sound and Vibration 306(1-2): 271-283. http://dx.doi.org/10.1016/j.jsv.2007.05.013.

17. Wang, Y.; Zhang, W.J. 1998. Stochastic vibration model of gear transmission systems considering speeddependent stochastic errors, Nonlinear Dynamics 17(2): 187-203. http://dx.doi.org/10.1023/A:1008389419585.

18. Wen, J.M.; Feng, Q. 2004. Two-stage stochastic model on rattling vibration with amplitude modulation, Shock and Vibration 11(5-6): 693-702. http://dx.doi.org/10.1155/2004/685892.

19. Walha, L.; Fakhfakh, T.; Haddar, M. 2009. Nonlinear dynamics of a two-stage gear system with mesh stiffness 
fluctuation, bearing flexibility and backlash, Mechanism and Machine Theory 44(5): 1058-1069.

http://dx.doi.org/10.1016/j.mechmachtheory.2008.05.008.

20. Ott, E.; Grebogi, C.; York, J.A. 1990. Controlling chaos, Phys Rev Lett 64 (11): 1196-1199. http://dx.doi.org/10.1103/PhysRevLett.64.1196.

21. Feng, G.; Chen, G.R. 2005. Adaptive control of discrete-time chaotic systems: a fuzzy control approach, Chaos, Solitons and Fractals 23: 459-467. http://dx.doi.org/10.1016/j.chaos.2004.04.013.

22. Lima, R.; Pettini, M. 1990. Suppression of chaos by resonant parametric perturbations, Phys Rev A (41): 726-728. http://dx.doi.org/10.1103/PhysRevA.41.726.

23. Braiman, Y.; Goldhirsch, I. 1991. Taming chaotic dynamic with weak perturbation, Phys Rev Lett 66(20): 2545-2548. http://dx.doi.org/10.1103/PhysRevLett.66.2545.

24. Pyragas, K. 1992. Continuous control of chaos by selfcontrolling feedback, Phys Lett A (170): 421-428. http://dx.doi.org/10.1016/0375-9601(92)90745-8.

25. Chang-Jian, C.W.; Hsu, H.C. 2012. Chaotic responses on gear pair system equipped with journal bearings under turbulent flow, Applied Mathematical Modelling 36(6): 2600-2613. http://dx.doi.org/10.1016/j.apm.2011.09.043

26. Wang, J.; Lim, T.C.; Li, M. 2007. Dynamics of a hypoid gear pair considering the effects of time-varying mesh parameters and backlash nonlinearity, Journal of Sound and Vibration 308(1-2): 302-329. http://dx.doi.org/10.1016/j.jsv.2007.07.042.
Jingyue Wang, Haotian Wang, Lixin Guo

ANALYSIS OF NONLINEAR DYNAMICS AND
CHAOS CONTROL IN GEAR TRANSMISSION
SYSTEM WITH STOCHASTIC PERTURBATION

$\mathrm{S}$ u m m a r y

In order to study the chaotic characteristics and control chaotic vibration in the gear transmission system. The dynamical equation and the state equation of gear transmission system are established by Newton's rule under considering stochastic perturbation of gear backlash, gear damping ratio, meshing frequency meshing stiffness and input torque fluctuation. The complex dynamics characters of gear transmission system are investigated. Five methods of controlling chaos are used to guide chaotic motions towards regular motions. Numerical simulation shows that the period doubling bifurcation, Hopf bifurcation and chaotic vibration exists in the gear transmission system. The effectiveness and feasibility of two kinds of feedback control method and three kinds of non-feedback control method to get rid of chaos by stabilizing the related unstable periodic orbit are verified.

Keywords: bifurcation, dynamics, chaos theory, control, feedback, computer simulation.

Received November 07, 2015 Accepted April 14, 2017 